\title{
Site-Specific Near-Infrared Fluorescent Labelling of Proteins on Cysteine Residues with meso-Chloro-Substituted Heptamethine Cyanine Dyes
}

\author{
Coline Canovas, ${ }^{\mathrm{a}}$ Pierre-Simon Bellaye, ${ }^{\mathrm{b}}$ Mathieu Moreau, ${ }^{\mathrm{a}}$ Anthony Romieu, ${ }^{\mathrm{a}, \mathrm{c}}$ Franck Denat, ${ }^{\mathrm{a}}$ and Victor Goncalves $* \mathrm{a}$
}

Near-infrared (NIR) fluorescence imaging is a promising new medical imaging modality. Associated with a targeting molecule, NIR fluorophores can accumulate selectively in tissues of interest and become valuable tools for the diagnosis and therapy of various pathologies. To facilitate the design of targeted NIR imaging agents, it is important to identify simple and affordable fluorescent probes, allowing rapid labelling of biovectors such as proteins, ideally in a site-specific manner. Here, we demonstrate that heptamethine cyanine based fluorophores, such as IR-783, that contain a chloro-cyclohexyl moiety within their polymethine chain can react selectively, at neutral $\mathrm{pH}$, with cysteine residues in proteins to give stable, site-specifically labelled conjugates, that emit in the NIR spectral window. This reaction is exemplified with the labelling of peptides and two protein models: albumin and a Fab' antibody fragment. The resulting fluorescent proteins are stable and suitable for in vivo NIR imaging applications, as shown on a mice model. This straightforward one-step procedure, that does not require the prior derivatisation of the fluorophore with a bioconjugatable handle, should facilitate the production and use of near-infrared labelled proteins in life sciences.

a. Institut de Chimie Moléculaire de I'Université de Bourgogne, UMR6302, CNRS, Université Bourgogne Franche-Comté, 9 avenue Alain Savary, 21000, Dijon (France)

b. Georges-François LECLERC Cancer Center - UNICANCER, 1 rue Pr Marion, 21079, Dijon (France)

c. Institut Universitaire de France, 1, Rue Descartes, Bâtiment MONGE, 75231, Paris (France)

Electronic Supplementary Information (ESI) available: Experimental procedures, characterization data, stability studies and biodistribution data.

\section{Introduction}

Near-infrared (NIR) fluorescence imaging is a promising new medical imaging modality that can potentially provide the sensitivity of nuclear medicine techniques, without the limitations associated with the handling and toxicity of radioactive materials. ${ }^{1}$ It often relies on the use of organicbased fluorophores that absorb and emit in the 650-900 nm (NIR-I) spectral window, which permits relatively deep photon penetration into tissue, and minimal tissue autofluorescence. The best example of such fluorescent organic dye is probably indocyanine green (ICG), which has been approved by the FDA for about 60 years to measure cardiac output, liver function or to study the anatomy of the retinal vessels. ${ }^{2}$ NIR fluorescence imaging has already clearly demonstrated its potential in preclinical research and will probably contribute to revolutionize cancer surgery by allowing image-guided intraoperative surgery. ${ }^{3,4}$

Current efforts focus on the design of targeted NIR-fluorescent agents, which are able to accumulate specifically in tissues of interest. Active targeting can be readily achieved through the covalent attachment of the NIR fluorophore to proteins, such as antibodies, that display excellent affinity and selectivity for their antigens. ${ }^{5-7}$ This conventional biolabelling is currently achieved through derivatisation of protein's lysine residues with fluorophores bearing a bioconjugatable moiety reactive towards primary amino groups (i.e., active esters and isothiocyanates). ${ }^{8}$ However, this random approach tends to be replaced with site-specific strategies, which aim at attaching the fluorescent organic dye to a specific position of the protein. ${ }^{9}$ Indeed, it is now well-documented that the number and positions of fluorescent labels on a protein sequence can have a dramatic impact on the biodistribution properties of the resulting imaging agent. ${ }^{10,11}$
A simple and efficient way to achieve site-specific labelling of proteins consists in introducing, at the intended position, a cysteine residue. Indeed, the greater nucleophilicity of thiols, compared to amines under physiological conditions, allows their selective labelling in the presence of electrophiles. ${ }^{12}$ Several NIR dyes able to react selectively with cysteines and related biothiols (i.e., homocysteine and glutathione) have been described in the literature. They usually consist in fluorophore scaffolds functionalised with a bioconjugatable handle such as maleimide, iodoacetamide, sulfone, alkene or 2cyanobenzothiazole groups. ${ }^{12,13}$ Although effective, these thiolreactive NIR probes are often hard to synthesize, eventually patented, and/or commercially available at prohibitive price (often $>100 \$$ per $\mathrm{mg}$ ), which may prevent their widespread use, in particular in preclinical research.

Here, we show that IR-783 (Fig. 1), a water-soluble NIR heptamethine cyanine dye carrying a central 4-chlorocyclohexyl ring within its polymethine chain (known as meso position), can directly label cysteine residues, under mild conditions.

By simply controlling the $\mathrm{pH}$ of labelling mixture, it is possible to achieve selective nucleophilic substitution of its meso-chlorine by thiols, as demonstrated on a peptide and two protein models. This post-synthetic derivatisation procedure of a cheap, commercially available, NIR-emitting cyanine dye $(<0.5 \$ / \mathrm{mg})$ promptly provides stable fluorescent bioconjugates suitable for in vivo imaging applications.

\section{Results and discussion}

The cyanine-based fluorophore IR-783 was first described and synthesised in 2004 by Patonay et al. ${ }^{14}$ Its spectral properties are suitable for in vivo applications, with a high molar absorption coefficient, excitation/emission maxima in the 
optical therapeutic window and an acceptable fluorescence quantum yield under physiological conditions. ${ }^{15}$ Furthermore, this NIR fluorophore has already been assessed in animal models and showed no systemic toxicity in mice, at doses up to $37.5 \mathrm{mg} / \mathrm{kg} /$ day for one month. ${ }^{16}$ Owing to these promising properties, IR-783 has been conjugated to various biomolecules (peptides, ${ }^{17}$ glucose derivatives, ${ }^{18,19}$ monoclonal antibodies, ${ }^{20}$ and even bacteriophages ${ }^{21}$ ). These fluorescent labellings required the prior reaction of $\mathbf{I R - 7 8 3}$ with a bifunctional crosslinker composed of i) a nucleophilic function (primary amine, phenol, or thiol) used to substitute the meso-chlorine atom, and ii) a terminal reactive handle, such as an activated ester, an isothiocyanate or a maleimide group. Alternatively, Gorris et al. described in 2011 the direct conjugation of IR-783 to proteins without pre-introducing a bioconjugatable tether onto the core structure of this fluorophore. ${ }^{22}$ The labelling was carried out through the substitution of the chlorine atom by protein's amine groups at $37^{\circ} \mathrm{C}$ and $\mathrm{pH} 8.4$. Interestingly, this reaction was associated with a significant hypsochromic shift in the absorbance of this heptamethine cyanine (colour of solution changed from green to blue) which allowed the monitoring of the reaction. The main limitations of this bioconjugation method were its non-site-specific nature, and the slow kinetics of substitution reaction leading to low conversion rates, even in alkaline conditions (ca. 20\% after $60 \mathrm{~h}$ ).

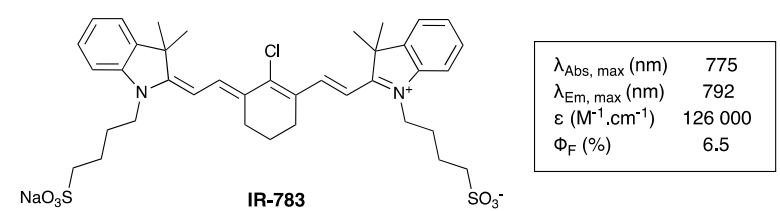

Fig. 1 Structure and main photophysical properties of the NIR-emitting cyanine dye IR783. $\lambda_{\mathrm{Abs}}$, max,$\lambda_{\mathrm{Em}, \max }$ and $\varepsilon$ were measured in PBS pH 7.4, at $25^{\circ} \mathrm{C} ; \Phi_{\mathrm{F}}$ value in PBS pH 7.4, at $25^{\circ} \mathrm{C}$, was obtained from literature. ${ }^{15}$

Since the kinetics of the substitution reaction depends on the nature of the nucleophile and the $\mathrm{pH}$ of the reaction, we hypothesised that, by judiciously choosing the bioconjugation conditions, one could achieve the specific labelling of cysteine residues, while keeping valuable spectral features of IR-783.

\section{Validation of the strategy on model peptides}

This strategy was first tested on a model peptide, AcCKYWGRGDS- $\mathrm{NH}_{2}$, which contains all common nucleophilic functions found in proteins (Fig. 2). ${ }^{23,24}$ The reaction was carried out at neutral $\mathrm{pH}$ (phosphate buffer, $\mathrm{PB}, \mathrm{pH}$ 7.1) to favor cysteine reactivity versus that of lysine. In the presence of an excess ( 25 equiv.) of IR-783, the sole product detected after $1 \mathrm{~h}$ was the mono-labelled peptide conjugate 1 (Fig. S1). The reaction was scaled up and allowed us to isolate 1 in $86 \%$ yield after purification by semi-preparative RP-HPLC. Fluorescent peptide 1 displayed photophysical properties in PBS $(\mathrm{pH} 7.4)$ typical of a "stabilised" Cy7 derivative with absorbance and emission maxima at 792 and $825 \mathrm{~nm}$ respectively (Fig S4). ${ }^{21}$
It has been reported in the literature that the reaction between meso-chloro-substituted heptamethine cyanine dyes and cysteine, or $\mathrm{N}$-terminal cysteinyl residues, can lead to the formation of amine-substituted cyanines. ${ }^{25}$ This reaction is caused by the substitution of the chlorine atom by the thiolate group of cysteine, followed by the spontaneous intramolecular displacement of sulphur by the $\alpha$-amino group of cysteine, through a five-membered cyclic transition state. It could be envisaged that a similar intramolecular reaction could occur in IR-783-labelled peptides and proteins, where thiol-conjugated IR-783 would be transferred to a nearby lysine residue. To assess whether this risk is real, a series of peptides was synthesized, in which the distance between the labelled cysteinyl residue and the lysine residue was varied (Table 1 ).

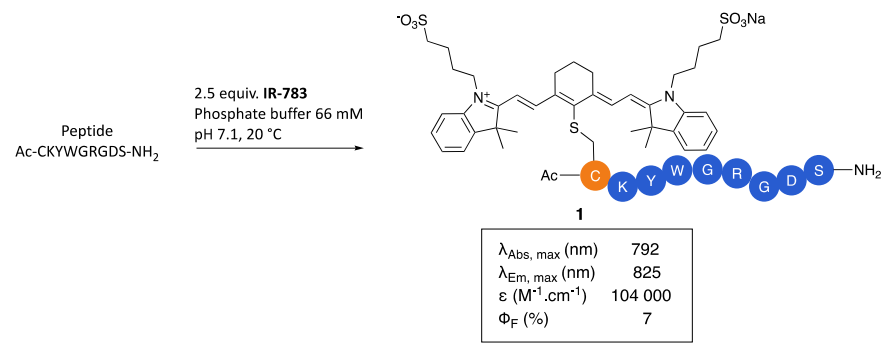

Fig. 2 Cysteine-selective labelling of a model peptide with IR-783. The spectral properties of 1 were recorded in PBS pH 7.4 at $25^{\circ} \mathrm{C}$. The fluorescence quantum yield was determined using IR-783 as reference $\left(\Phi_{\mathrm{F}}=6.5 \%\right.$ in PBS, $\left.\mathrm{pH} 7.4\right) .{ }^{15}$

Table 1. Assessment of the selectivity of the labelling reaction on model peptides

\begin{tabular}{rccc} 
Peptide substrate & $\begin{array}{c}\text { Degree of } \\
\text { labelling }\end{array}$ & $\begin{array}{c}\text { Product } \\
\mathrm{R}_{\mathrm{t}}(\mathrm{RP}-\mathrm{HPLC})\end{array}$ & $\begin{array}{c}\text { Product } \\
\lambda_{\text {(Abs, max }}\end{array}$ \\
\hline Ac-CKYWGRGDS-NH ${ }_{2}$ & 1 & $4.09 \mathrm{~min}$ & $791 \mathrm{~nm}$ \\
CKYWGRGDS-NH & 2 & $4.33 \mathrm{~min}$ & $706 \mathrm{~nm}$ \\
Ac-KCYWGRGDS-NH & 1 & $4.04 \mathrm{~min}$ & $788 \mathrm{~nm}$ \\
Ac-KYWGCRGDS-NH & 1 & $4.02 \mathrm{~min}$ & $789 \mathrm{~nm}$ \\
Ac-KYWGRGDSC-NH & 1 & $4.05 \mathrm{~min}$ & $788 \mathrm{~nm}$
\end{tabular}

The degree of labelling corresponds to the number of IR-783 dyes covalently bound to each peptide, as determined by RP-HPLC-MS analysis.

Each peptide was mixed with IR-783 (25 equivalents) in PB pH 7.4 , and the reaction mixture was analyzed by RP-HPLC after 1 $\mathrm{h}$ and $15 \mathrm{~h}$ of incubation at $25^{\circ} \mathrm{C}$.

All $\mathrm{N}$-acetylated peptides were completely converted, after $1 \mathrm{~h}$, into a product of monosubstitution, showing a maximum of absorption at ca. $790 \mathrm{~nm}$, characteristic of thiol-substituted heptamethine cyanine dyes. This result was independent of the distance between the cysteine and lysine residues and no changes were observed over the next $15 \mathrm{~h}$. In contrast, the peptide with a free $\mathrm{N}$-terminal cysteine residue afforded a disubstituted product, in which both the amine and thiol groups of cysteine were modified. This product exhibited a distinct UVVis absorption spectrum, with a maximum of absorption at 706 $\mathrm{nm}$, which is attributed to the formation of an aminesubstituted IR-783 adduct.

Although these results cannot definitively rule out the possibility of intramolecular transfer of IR-783 from cysteine residues to the side chain of lysine residues in a specific peptide or protein, this reaction is not favoured. More importantly, the eventual occurrence of such a reaction may be readily detected because it is associated with a large hypsochromic shift in $\mathrm{Cy} 7$ 
UV-vis spectrum. Such evolution has not been observed in the protein models that will be presented below.

Next, we evaluated the in vitro stability of 1 . Indeed, previous studies ${ }^{26-28}$ have shown that the alkenyl-thioether moiety may undergone further substitution reactions by other nucleophiles found in biological media at high concentrations, such as reduced glutathione (GSH). ${ }^{29}$ The fluorescent peptide conjugate 1 was found to be stable in foetal bovine serum at $37^{\circ} \mathrm{C}$ with 98\% intact peptide detected after $24 \mathrm{~h}$ and more than $92 \%$ after $55 \mathrm{~h}$ (Fig. S5). Degradation was slightly faster in the presence of $0.3 \mathrm{mM} \mathrm{GSH}$ at $37{ }^{\circ} \mathrm{C}$ with $83 \%$ of intact fluorescent bioconjugate persisting after $53 \mathrm{~h}$. Nevertheless, the thioether linkage appeared as sufficiently stable to withstand the biological environment for the time generally assumed to perform biodistribution studies.

\section{Cysteine-specific NIR labelling of a Fab' antibody fragment}

Encouraged by these first results, we sought to apply this method to a more relevant protein model. Fab' are monoclonal antibodies fragments that have been used as targeting agents for in vivo imaging applications. ${ }^{30}$ They can be prepared through the enzymatic digestion of the crystallisable fragment Fc of an IgG, followed by the selective reduction of the disulfide bridges of the hinge region. ${ }^{33} \mathrm{Fab}^{\prime}$ fragments retain an affinity comparable to their intact antibody counterparts but with faster pharmacokinetics in vivo. The reduced cysteines, in the hinge region of the Fab', are often regarded as ideal bioconjugation sites for the regiospecific labelling of the fragments without risks of interference with the antigen recognition site. ${ }^{32,33}$

Fab' fragments derived from pertuzumab, an anti-HER2 therapeutic monoclonal antibody, were prepared with a purity of $77 \%$ at $280 \mathrm{~nm}$ (the Fab' fragment was partially contaminated with light chain and heavy chain fragments; Fig S8). ${ }^{34}$ IR-783 (25 equiv.) was added to the $\mathrm{Fab}$ ' in $\mathrm{PB}$, at $37^{\circ} \mathrm{C}$ (Fig. $3 \mathrm{~A}$ ), and the reaction was monitored by RP-HPLC-MS analysis (Fig. S10). It is important to note that other thiol-based nucleophiles (such as reducing agents) should be removed from the reaction medium before the conjugation step. After $1 \mathrm{~h}$, a new peak was detected, assigned to the Fab' covalently labelled with two IR783 molecules (fluorescent Fab' conjugate 2), as indicated by the deconvoluted ESI mass spectrum (Fig. 3B). The labelling of Fab' further increased over time to reach $70 \%$ conversion after $26 \mathrm{~h}$. The specificity of the conjugation was confirmed by performing a control experiment on a Fab', whose cysteines had been previously capped by mild alkylation with iodoacetamide. In this case, no labelling was observed when the same bioconjugation conditions were used ( 25 equiv. of IR-783, $37^{\circ} \mathrm{C}$, 24 h; Fig. S11).

We finally sought to assess whether the efficiency and specificity of our approach were comparable to the conventional maleimide chemistry. ${ }^{13}$ Thus, we studied the labelling of pertuzumab Fab' with a commercially available Cy7maleimide derivative (Fig. S12). Preliminary tests indicated that the maleimide moiety of this Cy7 dye is more reactive than IR-
783, with a greater proportion of Fab' converted in $1 \mathrm{~h}(90 \%$ conversion in the presence of 15 equiv. of maleimide at $\mathrm{pH} 7.1$ ). However, the reaction was less specific, as shown by the presence of a significant amount of Fab' labelled with three cyanine molecules instead of two, which suggests the modification of some lysine residues.

These different experiments showed the feasibility of our strategy on complex proteins such as antibody fragments. Unfortunately, our inability to isolate the pertuzumab Fab' fragment with sufficient purity prevented us from evaluating the Fab'-(IR-783 $)_{2}$ conjugate in vivo. It prompted us to perform the labelling by IR-783 on an alternative protein model.

\section{NIR labelling of albumin and in vivo fluorescence imaging}

We undertook the conjugation of IR-783 to bovine serum albumin (BSA), a protein which contains a single free cysteine residue in its protein sequence (Cys-34).

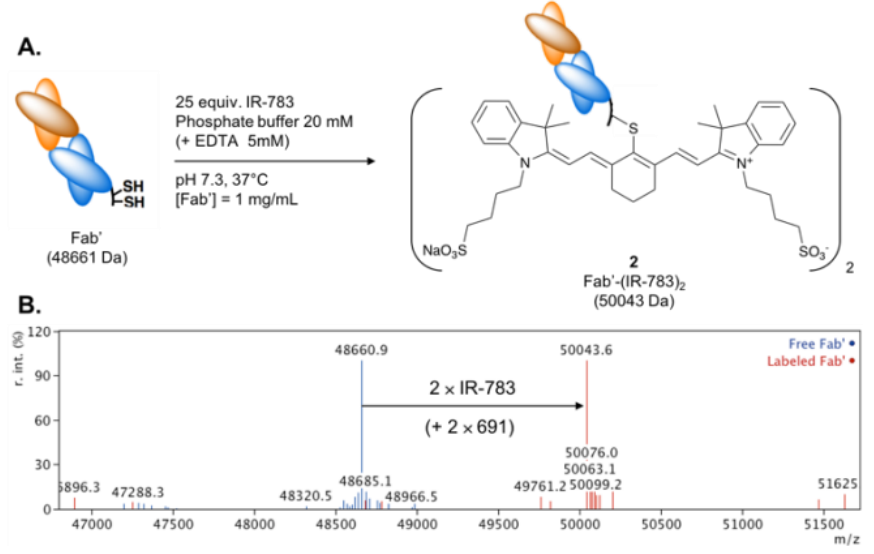

Fig. 3 (A) Labelling reaction of Fab' with IR-783. (B) Deconvoluted ESI-MS spectra (recorded in the positive mode) of free Fab' and Fab' labelled with two IR-783.

\section{NIR labelling of albumin and in vivo fluorescence imaging}

We undertook the conjugation of IR-783 to bovine serum albumin (BSA), a protein which contains a single free cysteine residue in its protein sequence (Cys-34). 10 equiv. of IR-783 were added to a solution of BSA at $2 \mathrm{mg} / \mathrm{mL}$ in $\mathrm{PB}(\mathrm{pH} 7.1)$ and at room temperature. The reaction was monitored by RP-HPLCMS analysis. After $1 \mathrm{~h}$, the conversion already reached $95 \%$. The excess of cyanine dye was removed after $5 \mathrm{~h}$, by size-exclusion chromatography, to afford the fluorescently-labelled albumin $\mathbf{3}$ with $>90 \%$ of purity (Fig. $4 \mathrm{~A}$ ). As before, the cysteine-specificity of the reaction was verified by ESI mass spectrometry (Fig. 4B) and UV-Vis absorbance spectroscopy (Fig. S17). Finally, the covalent nature of the bond between the fluorophore and albumin was confirmed by gel electrophoresis performed under denaturing conditions (Fig. 4C). Incubation of the conjugate $\mathbf{3}$ in human plasma at $37^{\circ} \mathrm{C}$ for $48 \mathrm{~h}$ did not lead to any detectable release of the fluorophore (Fig. S18).

The fluorescent BSA conjugate $\mathbf{3}$ was evaluated in BALB/c mice, healthy $(n=4)$ or bearing CT26 colon cancer syngeneic tumor cells on their flanks $(n=5) .{ }^{\ddagger}$ Fluorescence images were recorded $1 \mathrm{~h}, 4 \mathrm{~h}$ and $24 \mathrm{~h}$ after the injection of a dose of $30 \mu \mathrm{g} / \mathrm{mouse}$ (Fig. 5 and S20). The images at $1 \mathrm{~h}$ and $4 \mathrm{~h} \mathrm{p.i.} \mathrm{showed} \mathrm{an} \mathrm{uptake}$ of the fluorescence signal in the tumor, which can be explained 
by the enhanced permeability and retention (EPR) effect. After $24 \mathrm{~h}$, part of $\mathbf{3}$ had been eliminated from the circulation, leading to a higher contrast between the tumor region and surrounding normal tissues. The mice were euthanized and dissected, and the biodistribution of the fluorescent BSA conjugate in major organs was evaluated (Fig. S21-S22). We found a strong retention in the lung and liver of mice, which has been already observed in literature. ${ }^{35,36}$ The tumor/muscle and tumor/blood ratio were of 1.5 and 1.9 respectively.

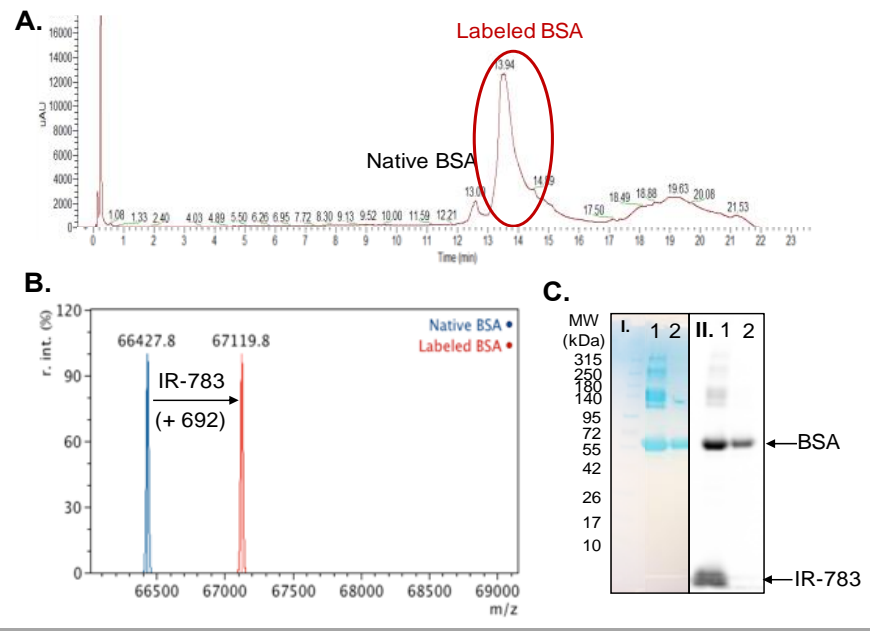

Fig. 4 (A) RP-HPLC elution profile of the purified fluorescent BSA conjugate 3 (detection at $280 \mathrm{~nm}$ ). (B) Deconvoluted ESI-MS spectra (positive mode) of free BSA and fluorescently labelled BSA. (C) SDS-PAGE analysis of the reaction mixture (line 1) and purified fluorescent BSA conjugate 3 (line 2) after Coomassie blue staining (left panel, I.) and by fluorescence (right panel, II.) with an excitation at $740 \mathrm{~nm}$ and emission at 790 $\mathrm{nm}$ (bandwidth of 20 and $40 \mathrm{~nm}$ respectively).
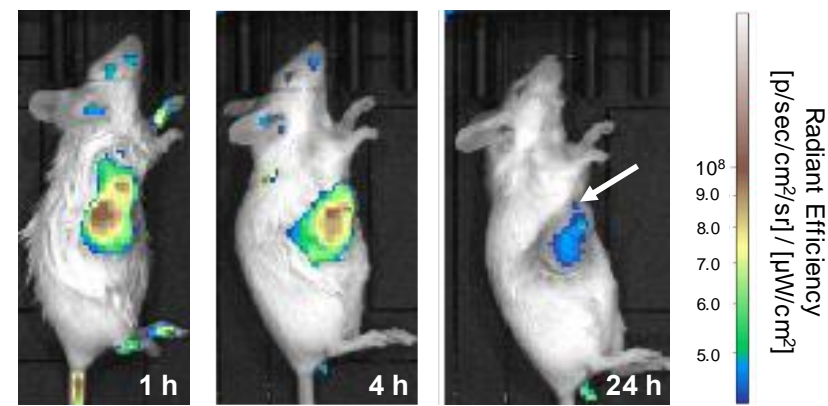

Fig. 5 Representative images of the biodistribution of the fluorescent BSA conjugate 3 by the measurement of fluorescence (excitation at $760 \mathrm{~nm}$ and emission at $845 \mathrm{~nm}$ (bandwidth of 20 and $40 \mathrm{~nm}$ respectively) in a living mouse bearing a CT26 tumor at $1 \mathrm{~h}$, $4 \mathrm{~h}$ and $24 \mathrm{~h}$ post-injection (p.i.). Fluorescence signal, displayed as radiant efficiency, is superimposed to white light images.

\section{Conclusions}

In summary, we have developed a novel straightforward onestep labelling strategy for proteins, based on the use of commercially available NIR-emitting cyanide dye IR-783. The conjugation reaction occurs selectively on cysteine residues at neutral $\mathrm{pH}$, through the selective substitution of the mesochlorine atom of this cyanine by thiol group of a cysteine residue. The resulting fluorescent bioconjugates are sufficiently stable in biological media to study their biodistribution in vivo.

We expect that this method will facilitate the design of welldefined immunoconjugates for NIR fluorescence imaging. Furthermore, we feel it is obvious that this innovative and easy to implement bioconjugate chemistry should be applicable to other families of organic-based fluorophores bearing a good leaving group within their core structure (e.g., xanthene dyes such as 9-substituted pyronins). Future work will focus on the evaluation of this strategy for the labelling of disulfide-reduced, full-length IgG antibodies.

\section{Conflicts of interest}

There are no conflicts to declare.

\section{Acknowledgements}

Financial support was provided by the French National Research Agency (ANR) under the programs Investissements d'Avenir (IMAPPI Equipex) and AAP Générique 2017 (project ZINELABEL), the CNRS and the Universite de Bourgogne'. C.C. was funded by the Ministry of Higher Education, Research and Innovation. This work is also part of the project Pharmaco-imagerie et agents théranostiques supported by the Conseil Régional de Bourgogne Franche-Comté through the Plan d'Action Régional pour I'Innovation (PARI) and by the European Union through the PO FEDER-FSE 2014/2020 Bourgogne program. A. R. thanks the Institut Universitaire de France (IUF) for financial support. The authors thank the "Plateforme d'Analyse Chimique et de Synthèse Moléculaire de l'Université de Bourgogne" (http://www.wpcm.fr) for access to analytical instrumentation.

\section{Notes}

₹ The animal study was conducted in accordance with the legislation on the use of laboratory animals (directive 2010/63/EU) and was approved by accredited Ethical committee (C2ea Grand Campus $\mathrm{n}^{\circ} 105$ ) and the French Ministries of Research (project \#9617) and Agriculture (A 21231016 EA).

\section{References}

1 J. V. Frangioni, Curr. Opin. Chem. Biol., 2003, 7, 626-634.

2 J. T. Alander, I. Kaartinen, A. Laakso, T. Pätilä, T. Spillmann, V. V. Tuchin, M. Venermo and P. Välisuo, Int. J. Biomed. Imaging, 2012, 2012, 940585.

3 S. Keereweer, P. B. A. A. V. Driel, T. J. A. Snoeks, J. D. F. Kerrebijn, R. J. B. de Jong, A. L. Vahrmeijer, H. J. C. M. Sterenborg and C. W. G. M. Löwik, Clin. Cancer Res., 2013, 19, 3745-3754.

4 A. V. DSouza, H. Lin, E. R. Henderson, K. S. Samkoe and B. W. Pogue, J. Biomed. Opt., 2016, 21, 080901.

5 E. A. Owens, M. Henary, G. El Fakhri and H. S. Choi, Acc. Chem. Res., 2016, 49, 1731-1740.

6 H. Kobayashi, P. L. Choyke and M. Ogawa, Curr. Opin. Chem. Biol., 2016, 33, 32-38. 
7 K. R. Zinn, M. Korb, S. Samuel, J. M. Warram, D. Dion, C. Killingsworth, J. Fan, T. Schoeb, T. V. Strong and E. L. Rosenthal, Mol. Imaging Biol., 2015, 17, 49-57.

8 M. S. T. Gonçalves, Chem. Rev., 2009, 109, 190-212.

9 Q.-Y. Hu, F. Berti and R. Adamo, Chem. Soc. Rev., 2016, 45, 1691-1719.

10 A. Perols, H. Honarvar, J. Strand, R. Selvaraju, A. Orlova, A. Eriksson Karlström and V. Tolmachev, Bioconj. Chem., 2012, 23, 1661-1670.

11 M. Rijpkema, D. L. Bos, A. S. Cornelissen, G. M. Franssen, D. M. Goldenberg, W. J. Oyen and O. C. Boerman, Mol. Imaging, 2015, 14, 348-355.

12 P. Adumeau, S. K. Sharma, C. Brent and B. M. Zeglis, Mol. Imaging Biol., 2016, 18, 1-17.

13 G. T. Hermanson, Bioconjugate Techniques, Elsevier, 2013.

14 G. Patonay, J. Salon, J. Sowell and L. Strekowski, Molecules, 2004, 9, 40-49.

15 L. Wang, J. Jin, X. Chen, H.-H. Fan, B. K. F. Li, K.-W. Cheah, N. Ding, S. Ju, W.-T. Wong and C. Li, Org. Biomol. Chem., 2012, 10, 5366.

16 X. Yang, C. Shi, R. Tong, W. Qian, H. E. Zhau, R. Wang, G. Zhu, J. Cheng, V. W. Yang, T. Cheng, M. Henary, L. Strekowski and L. W. K. Chung, Clin. Cancer Res., 2010, 16, 2833-2844.

17 G. Guan, Y. Lu, X. Zhu, L. Liu, J. Chen, Q. Ma, Y. Zhang, Y. Wen, L. Yang, T. Liu, W. Wang, H. Ran, X. Qiu, S. Ke and Y. Zhou, Sci.c Rep., 2015, 5, 15244.

18 C. Li, T. R. Greenwood and K. Glunde, Neoplasia, 2008, 10, 389-398.

19 R. Sharma, W. Wang, J. C. Rasmussen, A. Joshi, J. P. Houston, K. E. Adams, A. Cameron, S. Ke, S. Kwon, M. E. Mawad and E. M. Sevick-Muraca, Am. J. Physiol.-Heart Circ. Physiol., 2007, 292, H3109-H3118.

20 F. Feng, H. Zhang, Z. Zhu, C. Li, Y. Shi and Z. Zhang, Luminescence, 2014, 29, 614-620.

21 S. A. Hilderbrand, K. A. Kelly, R. Weissleder and C.-H. Tung, Bioconj. Chem., 2005, 16, 1275-1281.

22 H. H. Gorris, S. M. Saleh, D. B. M. Groegel, S. Ernst, K. Reiner, H. Mustroph and O. S. Wolfbeis, Bioconj. Chem., 2011, 22, 14331437.

23 C. Canovas, M. Moreau, C. Bernhard, A. Oudot, M. Guillemin, F. Denat and V. Goncalves, Angew. Chem. Int. Ed., 2018, 57, 1064610650.

24 S. Arumugam, J. Guo, N. E. Mbua, F. Friscourt, N. Lin, E. Nekongo, G.-J. Boons and V. V. Popik, Chem. Sci., 2014, 5, 1591-1598.

25 L.-Y. Niu, H.-R. Zheng, Y.-Z. Chen, L.-Z. Wu, C.-H. Tung and Q.-Z. Yang, Analyst, 2014, 139, 1389-1395.

26 S.-Y. Lim, K.-H. Hong, D. I. Kim, H. Kwon and H.-J. Kim, J. Am. Chem. Soc., 2014, 136, 7018-7025.

27 X. Wang, J. Lv, X. Yao, Y. Li, F. Huang, M. Li, J. Yang, X. Ruan and B. Tang, Chem. Commun., 2014, 50, 15439-15442.

28 R. R. Nani, J. B. Shaum, A. P. Gorka and M. J. Schnermann, Org. Lett., 2015, 17, 302-305.

29 J. P. Richie, L. Skowronski, P. Abraham and Y. Leutzinger, Clin. Chem., 1996, 42, 64-70.

30 H. Ding, M. M. Carlton, S. P. Povoski, K. Milum, K. Kumar, S. Kothandaraman, G. H. Hinkle, D. Colcher, R. Brody, P. D. Davis, A. Pokora, M. Phelps, E. W. Martin and M. F. Tweedle, Bioconjug. Chem., 2013, 24, 1945-1954.

31 C. Rader, Curr. Protoc. Protein Sci. 2009, 55, 6.9.1-6.9.14.

32 D. A. Richards, A. Maruani and V. Chudasama, Chem. Sci., 2017, 8, 63-77.

33 V. Chudasama, A. Maruani and S. Caddick, Nature Chem., 2016 8, 114-119.
34 L. Gianni, T. Pienkowski, Y.-H. Im, L. Roman, L.-M. Tseng, M.-C. Liu, A. Lluch, E. Staroslawska, J. de la Haba-Rodriguez, S.-A. Im, J. L. Pedrini, B. Poirier, P. Morandi, V. Semiglazov, V. Srimuninnimit, G. Bianchi, T. Szado, J. Ratnayake, G. Ross and P. Valagussa, Lancet Oncol., 2012, 13, 25-32.

35 M. R. Powers, F. A. Blumenstock, J. A. Cooper and A. B. Malik, J. Cell. Physiol., 1989, 141, 558-564.

36 F. Basuli, C. Li, B. Xu, M. Williams, K. Wong, V. L. Coble, O. Vasalatiy, J. Seidel, M. V. Green, G. L. Griffiths, P. L. Choyke and E. M. Jagoda, Nucl. Med. Biol., 2015, 42, 219-225. 